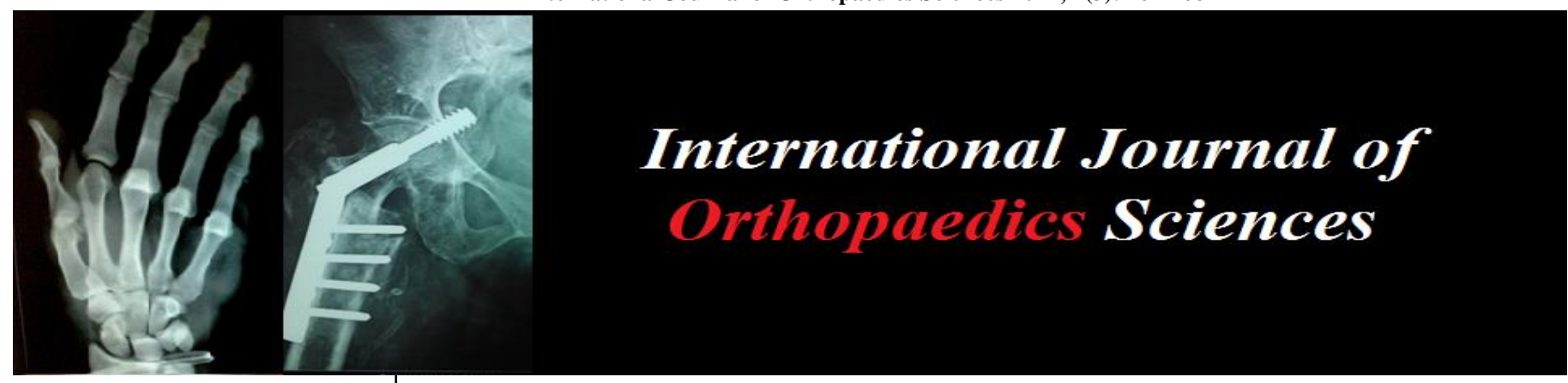

E-ISSN: 2395-1958

P-ISSN: 2706-6630

IJOS 2021; 7(3): 264-268

(C) 2021 IJOS

www.orthopaper.com

Received: 25-05-2021

Accepted: 27-06-2021

Dr. K Hari Krishna Reddy Associate Professor,

Department of Orthopaedics, Narayana Medical College and Hospital, Chintareddypalem, Nellore, Andhra Pradesh, India

Dr. B Manmohan Sai

Postgraduate Resident,

Department of Orthopaedics

Narayana Medical College and

Hospital, Chintareddypalem,

Nellore, Andhra Pradesh. India

\section{A prospective study of outcome in management of neglected fracture neck of femur by internal fixation and tensor fascia lata muscle pedicle graft}

\author{
Dr. K Hari Krishna Reddy and Dr. B Manmohan Sai
}

DOI: https://doi.org/10.22271/ortho.2021.v7.i3d.2758

\section{Abstract}

Background: Fractures of the neck of the femur have always presented great challenges to Orthopaedic Surgeons and remain in many ways today the unsolved fracture as far as treatment and results are concerned.

Methods: Early anatomical reduction, compression of the fracture, and rigid internal fixation are used to promote union, but the surgeon probably has less control over osteonecrosis as the blood supply to the femoral head after femoral neck fracture is quite precarious.

Many different devices have been devised for internal fixation of femoral neck fractures, but currently two are commonly used. They are multiple cannulated screws and Dynamic Hip Screw with an additional anti-rotation screw.

We studied 14 cases of 1 month-to-one year old fracture neck of femur. All of them had viable head of femur. There was varying degree of resorption of neck of femur, One patient had pathological fracture neck of femur but head of femur was viable.

12 cases were treated with closed reduction, internal fixation with cannulated cancellous screws, augmented with Tensor fascia lata (TFL) muscle pedicle graft to the neck of femur .2 cases were treated with closed reduction, internal fixation with Dynamic hip screw, augmented with TFL Muscle pedicle graft to the neck of femur.

Results: 12 cases showed union of fracture, 2 cases were lost in follow up, all 12 patients were able to return to routine daily activities, and one case had avascular necrosis (AVN) with poor function of hip. Conclusion: Fracture neck of femur new or old when treated with stable reduction, alignment as per Garden's index, rigid internal fixation with augmentation by Tensor fascia muscle pedicle grafting for reestablishment of vascularity to head of the femur resulted in $100 \%$ union.

Key words: fracture neck of femur, TFL Muscle pedicle graft, internal fixation

\section{Introduction}

Fractures of the neck of the femur have always presented great challenges to orthopaedic surgeons and remain in many ways today the unsolved fractures as far as treatment and results are concerned. Non-union and avascular necrosis form two main complications of this fracture, especially if patient presents late. Femoral neck fractures in young patients usually are caused by high-energy trauma and often are associated with multiple injuries and high rates of osteonecrosis and nonunion. Femoral neck fractures usually are entirely intracapsular, and, common to all intracapsular fractures, the synovial fluid bathing the fracture may interfere with the healing process.

The femoral neck essentially has no periosteal layer, all healing must be endosteal. Angiogenic-inhibiting factors in synovial fluid also can inhibit fracture repair. These factors, along with the precarious blood supply to the femoral head, make healing unpredictable and nonunions are fairly frequent due to the proximal part of the fracture not being held in alignment with the distal fracture end. There is always the possibility of proximal end rotating and resulting in torsion of re-established vascular channels.

We have done a prospective study of 14 patients with fracture neck of femur which is 1 month to1 year old, with viable head of the femur treated by closed reduction, internal fixation with cannulated cancellous screws, dynamic hip screw, augmented with TFL muscle pedicle graft

\section{Dr. K Hari Krishna Reddy}

Associate Professor,

Department of Orthopaedics,

Narayana Medical College and

Hospital, Chintareddypalem,

Nellore, Andhra Pradesh, India 
to the neck of the femur Two patients lost to follow up. Hence we are presenting analysis of the results of 12 patients treated by this method. The study is to assess the improved capability healing of fracture neck of the femur with restoration of blood supply to head of femur.

\section{Subjects and Methods}

14 patients operated between 2016 and 2019 with a mean follow-up of $2 \frac{1}{2}$ years. (range 6 months to 4 years) were included. All patients of displaced femoral neck fractures were treated by closed reduction, internal fixation with cannulated cancellous screws/ Dynamic hip screw(two cases), augmented with TFL Muscle pedicle graft/Fibular strut graft to the neck of femur (two cases). Patients with femoral neck fracture with an inability to walk (due to reasons other than the femoral neck fracture), or with a life expectancy of less than five years, or with an inability to cooperate in the postoperative program were excluded from the study. All young patients with a displaced femoral neck fracture presenting late (1month to 1year old) were included in the study.

Out of 14 patients, 10 were males and 4 were females. Their age ranged from 15 years to 48 years (average age 27.8years). Fractures were more than one month old at the time of operation. Road traffic accident was the commonest mode of trauma. The left side was involved in 7 patients and the right side in 7. Majority of the fractures (13/14 cases) in our series were trans-cervical (one pathological fracture). 1/14 cases was basicervical. All the patients were kept in below knee skin traction/ skeletal traction while waiting for surgery.

\section{Operative Technique}

While the patients were in supine position on traction table.closed reduction was attempted by Whitman's method and internal fixation was performed for fracture neck of the femur with cannulated cancellous screws/ Dynamic hip screw through lateral incision under $\mathrm{C}$-arm guidance. (Fig. 1\&2)

The lateral incision was extended proximally and converted to Smith Petersen approach. .The groove between Sartorius and TFL was identified, and an incision was made in muscle fibres of TFL, $2.5 \mathrm{cms}$ behind the anterior edge of the muscle. Isolated anterior fibres of TFL were elevated, and deep fibres were sectioned. A segment of iliac crest $2.5-5 \mathrm{cms}$ long and 1 cms broad was osteotomised and retracted down along with anterior fibres of TFL. (Fig.3).

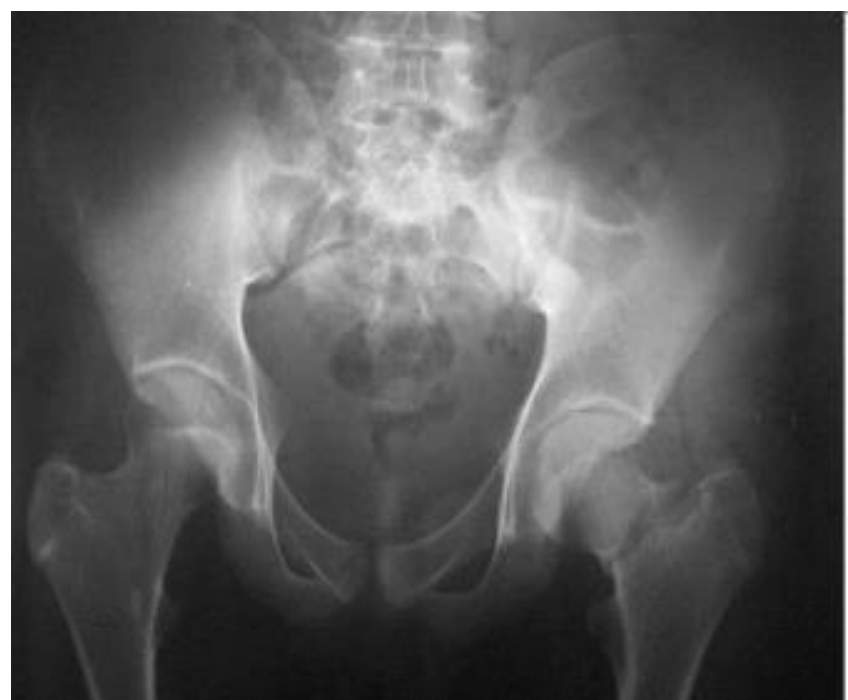

Fig 1: Showing Pre Operative $X$ ray of Pelvis with both Hips A-P view Showing Basic-Cervical Fracture of Neck of left Femur

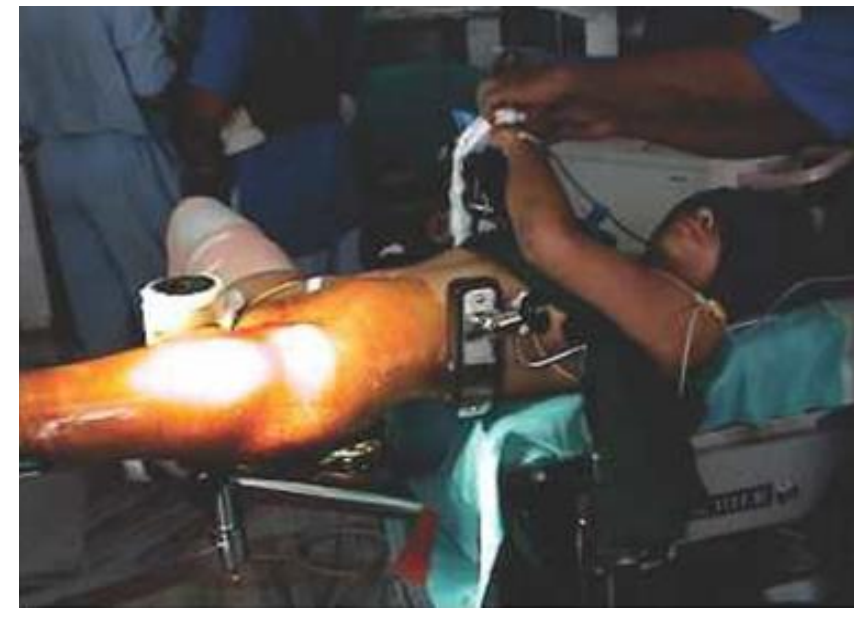

Fig 2: Showing Positioning of the Patient on Fracture Table after Closed Reduction

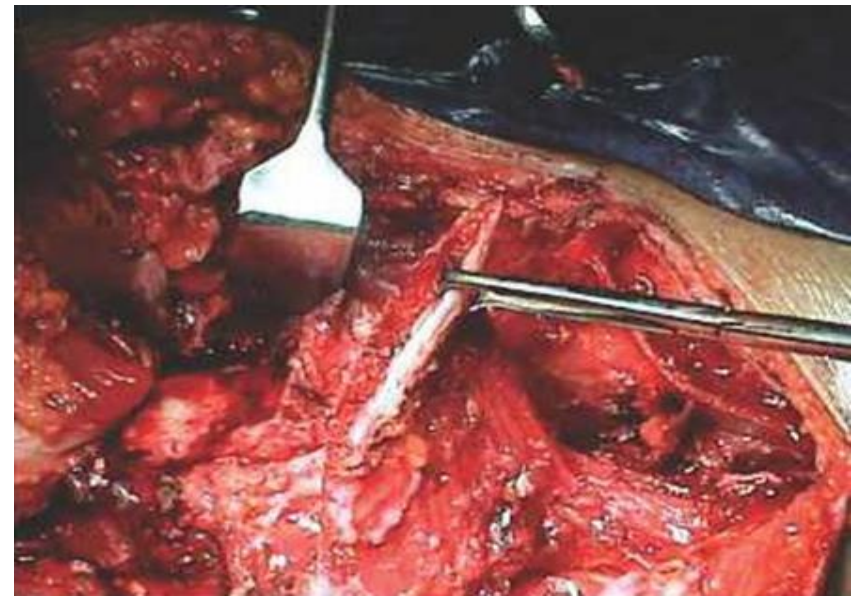

Fig 3: Showing Tensor Fascia Lata Muscle Pedicle Graft with a Segment of Iliac Crest

The exposed gluteus minimus muscle was erased from the outer surface of the ilium and retracted down, and the straight and reflected heads of rectus femoris were sectioned. The anterior capsule of the hip was opened, using an inverted Tshaped incision. A notch was made on the anterior surface of the neck at the sub-capital region. (Fig. 4)

The harvested Tensor Fascia Lata muscle pedicle graft was placed on the anterior surface of the neck and pegged into the notch and fixed with a cortical screw/ S S wire (one case). Wound was closed in layers over a drain. (Fig. 5,6)

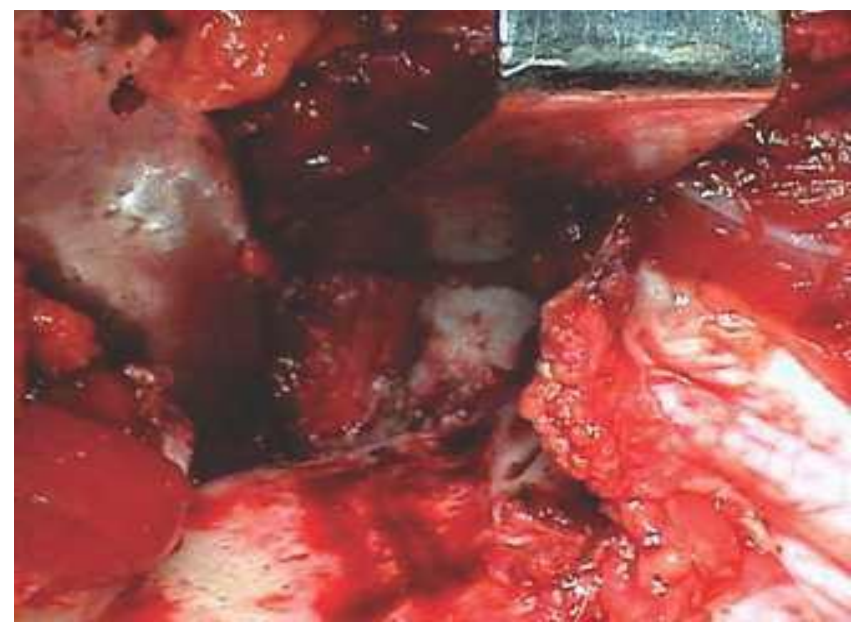

Fig 4: Showing Notch on Anterior Surface of Neck of Femur 


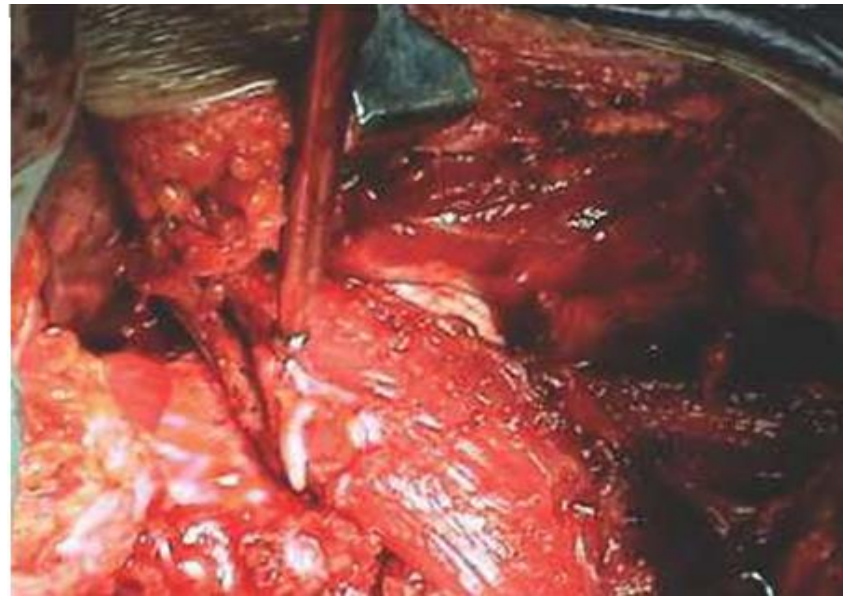

Fig 5: Showing Fixation of the Muscle Pedicle Graft with a Cortical Screw.

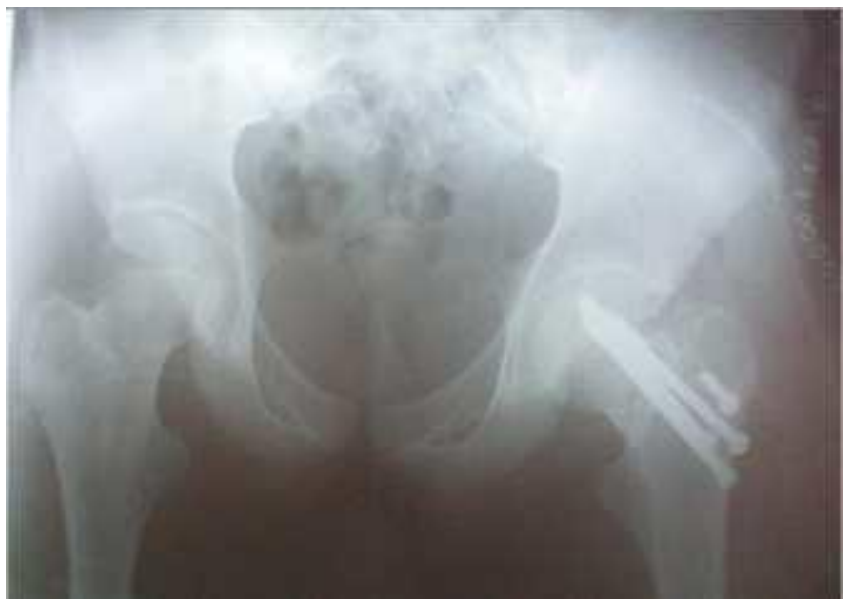

Fig 6: Showing Post Operative $X$ ray of Pelvis with both Hips A-P with Cannulated Cancellous Screws In situ.

\section{After care}

In post operative period lower limbs were kept in abduction splint. Assisted hip movements were started early in post operative period. Crutch walking, non weight bearing on affected leg was started after 6 weeks. Patients were advised partial weight bearing walking from 3 months, and full weight bearing walking was advised after radiological union. All patients returned to most of their routine daily activities except one (case-9) after radiological union (fig. 7,8).

\section{Discussion}

Fractures of the neck of the femur have always presented great challenges to orthopaedic surgeons and remain in many ways today the unsolved fracture as far as treatment and results are concerned.

Anatomical reduction, impaction and rigid internal fixation are essential in treating femoral neck fractures. Muscle pedicle bone grafting has been advocated by many investigators along with rigid internal fixation to prevent non union and AVN of the femoral head.

Femoral neck fractures in young patients usually are caused by high-energy trauma and often are associated with multiple injuries and high rates of osteonecrosis and nonunion. Union of fracture neck of femur apparently depends on;

1. The extent of the injury, such as the amount of displacement, the amount of comminution, and whether the circulation has been disturbed.

2. The adequacy of the reduction

3. The adequacy of fixation

4. Augmenting rigid fixation with vascular muscle pedicle graft to improve early revascularization \& reestablishment of blood supply to head of femur.

\section{Factors affecting the union of fractures of femoral neck} are

1. Femoral neck fractures usually are entirely intracapsular, and, common to all intra-capsular fractures, the synovial fluid bathing the fracture may interfere with the healing process.

2. The femoral neck essentially has no periosteal layer, and all healing must be endosteal. Angiogenic inhibiting factors in synovial fluid also can inhibit fracture repair.

3. These factors, along with the precarious blood supply to the femoral head, make healing unpredictable and nonunions fairly frequent due to the proximal part of the fracture not being held in alignment with the distal fracture end there is always the possibility of proximal end rotation and resulting in torsion of reestablished vascular channels

Factors affecting the union of fractures of femoral neck are

\begin{tabular}{|c|c|c|c|c|c|c|c|c|}
\hline Case & Age/ sex & Fracture duration & Neck & Viability of head & Joint change & Follow up & Results & Complications \\
\hline 1 & $15 / \mathrm{F}$ & 1 year & resorbed & viable & Nil & 6 months & 6 & Nil \\
\hline 2 & $32 / \mathrm{M}$ & 1 month & Intact & Viable & Nil & 2years & 5 & Nil \\
\hline 3 & $46 / \mathrm{M}$ & 2 months & partial & Viable & Nil & 2years & 6 & Nil \\
\hline 4 & $48 / \mathrm{M}$ & 1 month & Intact & Viable & Nil & 2 years & 6 & Nil \\
\hline 5 & $17 / \mathrm{F}$ & Pathological fracture & destruction & Viable & Nil & 4 years & 8 & Nil \\
\hline 6 & $17 / \mathrm{M}$ & 1 month & Intact & Viable & Nil & 4years & 5 & Nil \\
\hline 7 & $28 / \mathrm{M}$ & 1 month & Intact & Viable & Nil & Lost to & -- & Nil \\
\hline & & & & & & & Followup & AVN (good function) \\
\hline 8 & $19 / \mathrm{M}$ & 1 month & Intact & Viable & Nil & 4years & 6 & AVN \\
\hline 9 & $30 / \mathrm{M}$ & 3 months & partial & Viable & Nil & 4years & 6 & Nil \\
\hline 10 & $35 / \mathrm{F}$ & 2 months & Intact & Viable & Nil & lost to & -- & Nil \\
\hline & & & & & & & Followup & Nil \\
\hline 11 & $37 / \mathrm{F}$ & 2 month & Intact & Viable & Nil & 4years & 6 & Nil \\
\hline 12 & $16 / \mathrm{M}$ & 1 month & Intact & Viable & Nil & 4years & 6 & Nil \\
\hline 13 & $28 / \mathrm{M}$ & 6 months & partial & Viable & Nil & 6months & 6 & \\
\hline 14 & $21 / \mathrm{M}$ & 1 month & Intact & Viable & Nil & 4years & 6 & \\
\hline
\end{tabular}

As with nonunion, the development of osteonecrosis correlates with the extent of initial trauma and the displacement of the fracture, with some question concerning the tamponade effect of the intracapsular hematoma. 
Radiographic evidence of osteonecrosis does not always indicate a poor functional result, and the late effects of osteonecrosis may take many years to develop.

The method of fracture fixation can have an effect on the rate of osteonecrosis and nonunion with femoral neck fractures. The use of a single large compression hip screw for fixation of femoral neck fractures was shown by Madsen et al. and Christie et al. to result in lower rates of union for intracapsular fractures. In intracapsular femoral neck fractures with poor bone quality of lateral cortex i.e osteoporosis the use of a hip compression screw with side plate is indicated . Garden originally described his alignment index as a guide to adequacy of a given reduction.

On the anteroposterior view, the angle between the central compressive trabeculae within the femoral head and the medial cortex of the femur is measured. According to Garden, this angle is normally 160 degrees. On the lateral view, the major trabeculae are in the same axis as the axis of the femoral neck or lie at an angle of 180 degrees. Garden showed higher rates of union and lower rates of osteonecrosis if the compressive trabeculae of the femoral head were aligned with the medial cortex of the femur on the anteroposterior view between an angle of 155 degrees and 180 degrees.

On the lateral view, he described an acceptable reduction to be within the same range of 155 to 180 degrees, although he strived to correct all of the anterior angulation. He also showed that osteonecrosis increased from $7 \%$ to $65 \%$ when the alignment index was less than 155 degrees or more than 180 degrees in either view. He found that osteonecrosis was universal when, in the anteroposterior view, fractures were reduced with an alignment index of less than 150 degrees or more than 185 degrees, implicating angular and rotational malunion in the incidence of osteonecrosis.

We have done a prospective study of 14 patients with fracture neck of femur of 1 month to 1 year old. All the cases had a viable head of femur which is a pre-requisite, four cases presentented with varying degrees of absorption of the neck. One case with a pathological fracture-GCT showed gross destruction of the neck. All cases showed union of fracture (mean duration -6 months) It is noticed inspite of the union two cases (14.28\%) revealed segmental collapse due to AVN, inspite of the AVN one patient had good function.

The study was to assess the improved capability healing of fracture neck of femur with restoration of blood supply to head of femur.

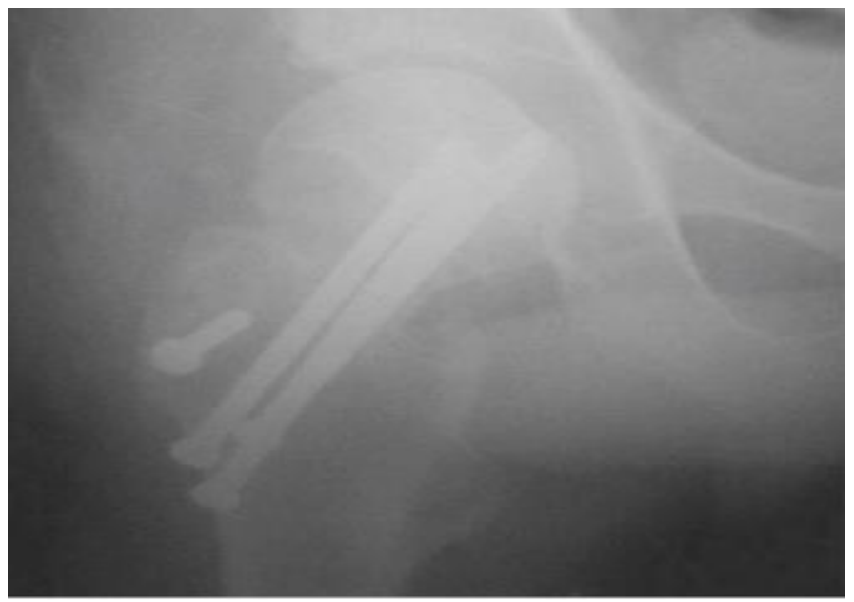

Fig 7: Showing Immediate Post Operative $X$ ray of Right Hip A-P view with Cannulated Cancellous Screws In situ (case 9).

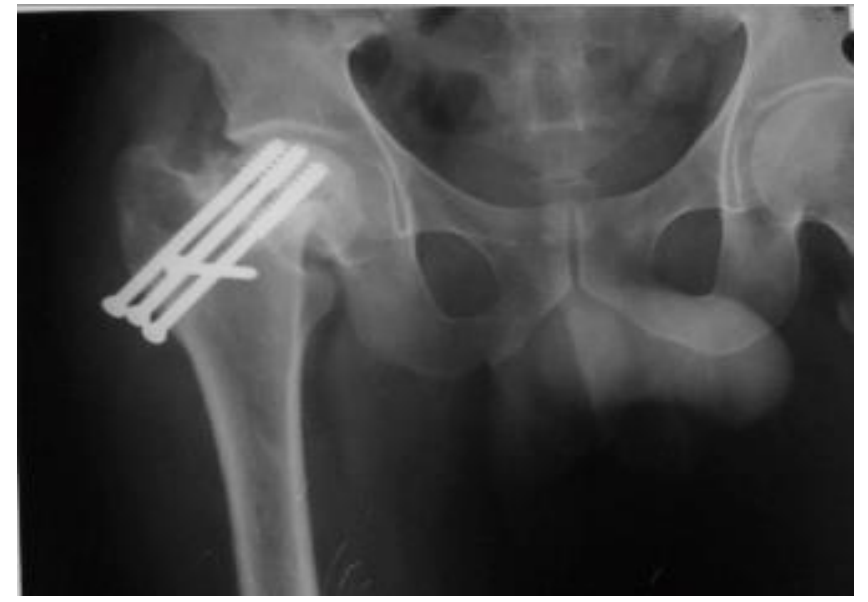

Fig 8: 6 Months Follow up X ray of right Hip A-P View Showing Collapse of Supero-lateral Portion of Head of Femur (AVN) (case 9).

\section{Conclusion}

Fracture neck of Femur-new or old-when treated with stable reduction, alignment as per Garden's index, rigid internal fixation with augmentation by Tensor Fascia Lata muscle pedicle grafting for re-establishment of vascularity to head of femur resulted in $100 \%$ union. From our study, we conclude that augmentation using muscle pedicle graft helps patient recover faster and return to daily routine activities, also gainful employment.

\section{Reference}

1. Baksi DP Internal Fixation of Ununited Femoral Neck Fractures Combined with Muscle-Pedicle Bone Grafting. J Bone Joint Surg [Br] 1986;68-B:239-45

2. McMurray TP, Ununited fractures of the neck of femur. J Bone Joint Surg 1936;18:319 27.

3. Reich RS. Ununited fracture neck of the femur treated by high oblique osteotomy. J Bone Joint Surg 1941;23:141 58.

4. Blount WP. Blade plate internal fixation for high femoral osteotomies. J Bone Joint Surg 1943;25:319-39.

5. Leadbetter GW. Cervical axial osteotomy of the femur A preliminary report. J Bone Joint Surg 1944;26:713- 20.

6. Stewart MJ, Wells RE. Osteotomy and Osteotomy combined with bone grafting for non union following fracture of the femoral neck J Bone Joint Surg [Am] 1956;38A:33-49

7. King T. Closed operation for intracapsular fracture of the neck of the femur. Final result in recent and old cases. $\mathrm{Br}$ J Surg 1939:26:721-48.

8. Dickson JA. The high geometric osteotomy with rotation and bone graft, for ununited fracture of the neck of the femur- a preliminary report. J Bone Joint Surg 1947;29:1005-18.

9. Dickson JA. The "unsolved" fracture. A protest against defeatism. J Bone Joint Surg [Am],1953;35A:805-22.

10. Smith FB. The effects of rotary and valgus malpostions on blood supply to the femoral head - Observation at arthroplasty. J Bone Joint Surg [Am],1956;38A:33-49.

11. Garden RS. Low angle fixation in fractures of the femoral neck J Bone Joint Surg [Br],1961;43B:647-63.

12. Meyers MH, Harvey JP Jr, Moore TM. Treatment of displaced subcapital and transcervial fractures of the femoral neck by muscle pedicle bone graft and internal fixation. A preliminary report on 150 cases. J Bone Joint Surg [Am] 1973;55A:257-74. 
13. Baksi DP. Treatment of post traumatic avascular necrosis of the femoral head by multiple drilling and muscle pedicle bone grafting J Bone Joint Surg [Br] 1983;65B:268-73.

14. Baksi DP. Treatment of Osteonecrosis of the Femoral Head by Drillng and Muscle-Pedicle Bone Grafting. J Bone Joint Surg [Br] 1991;73-B:241-5. 